\title{
A Survey on Driver Behavior Detection Techniques
}

\author{
Ishita Seth
}

\begin{abstract}
The objective of this paper is to detect the car driver behavior. Many factors can influence the behavior of the driver that includes fatigue, distraction, eye-blinking, taking eyes off from the road, time of the driving etc. The in appropriate behavior while driving the car can leads to accidents that in return damages one's life or the vehicle. The papers discuss the various techniques to monitor the driver behaviors and describes the advantages and disadvantages of the methods used to detect the driver behavior in a car.

Keywords : Automotive, Safety, Active Safety, Passive Safety, terms suggests is for preventing the accidents by providing the warnings or the alerts to the drivers. Head-Up Display, Anti-Lock Braking Systems, Electronic Stability Control, Tire Pressure Monitoring System, Lane Departure Warning System, Adaptive Cruise Control, Driver Monitoring , Blind Spot Detection and Night Vision System.
\end{abstract}

\section{INTRODUCTION}

Currently, car accident is one of the common issues around the global, especially in India. In 2018, India reported 467,044 road accidents, there was an increase of $0.5 \%$ comparison to the 2017. Also, India accounts 65 of the world's road traffic accidents as per the World Health organization report [1]. According to the Ministry of Road Transport and Highways most of the accidents happens due to Human error that includes drunken driver, consumption of alcohol, traffic rules violation and using of mobile phones while driving the car.

To provide the safety features to the driver and passengers many of the OEM's are working closely on the handsfree devices. Driving is the most complex decision making as there is a complex relationship exists between the driver and the environment around [2]. Recent studies have shown that the driver's emotions play a vital role in the safe or unsafe driving mode. There are number of accidents takes place every single day is being carried out also by driver's behavior. One's emotion can be responsible for the entire passenger's life. The emotions such as fatigue, stress, fear, distraction, anger plays a considerable role in the driving [3]. Along with there are other factors like discomfort caused by long driving hours, workload, attention, traffic is also can be the reason.

Majorly there are thirteen kinds of distraction activities that is proposed in [4] drinking or eating, outdoor people, event or object, talking or listening on mobile phone and using in-vehicle-technologies etc. Distraction can be caused in several ways

1) Looking away from the road called as visual distraction.

2) Responding to cell phone called as Auditory distraction.

3) Lost in the thoughts called as Cognitive distraction

4) Adjusting volume of radio called as Biomechanical distraction

Broadly, the Safety system is divided into the Active Safety and Passive Safety as shown in Figure 1. Active Safety as the terms suggests is for preventing the 
accidents by providing the warnings or the alerts to the drivers. Head-Up Display (HUD), Anti-Lock Braking Systems (ABS), Electronic Stability Control (ESC), Tire Pressure Monitoring System (TPMS), Lane Departure Warning System (LDWS), Adaptive Cruise Control (ACC), Driver Monitoring System (DMS), Blind Spot Detection (BSD) and Night Vision System (NVS) are common Active Safety System. Whereas Passive Safety is to limit the chance of accident such as Airbags, Seatbelts, Whiplash Protection System etc. are common Passive Safety Systems deployed in vehicles these days.

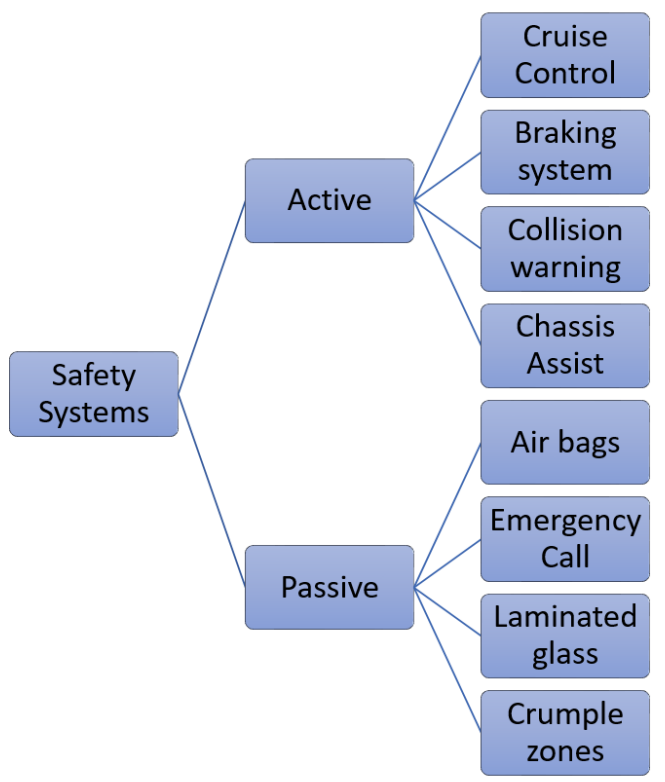

Figure 1 : Safety System

Fatigue is considered as the main factor and causes almost $25 \%-30 \%$ of road crashes [5]. Also, the immature driving behavior that included driving with more speed on the empty roads, opposing the traffic rules etc. The accident rates are particularly higher in ASEAN region than other countries [6]. So, this this needs to be taken care well in advance to protect the vehicle and the passengers from the loss.

SECTION II.

\section{Driver Behavior Detection Techniques:}

Since human behavior is the main cause of accidents so it is highly recommended to detect the driver behavior for safety of passengers as well as driver. As mentioned above the vehicle safety system can be active as well as passive 1 . This paper provides the techniques to detect the driver behavior when the car is moving and the car is stationary.

\section{Moving Vehicle:}

The first approach is to detect the behavior of the driver using a car mounted camera [7]. In the vehicle mounted camera it will generate the warning to the driver using a beep sound when it detects the fatigue or drowsiness in the driver behavior. The camera focus on the driver head to visualize the behavior of the driver. In [8] the authors designed a camera to detect drive fatigue and alert signal will generate. The camera facing the driver's face and notifies in case of fatigue. Considering the cost, it is cheaper as compared to any other approach and widely used to detect the driver behaviour

Advantage using this approach is cost-effective and power-efficient processors, can deliver abundant benefits to drivers and passengers.

Disadvantage is computational complexity.

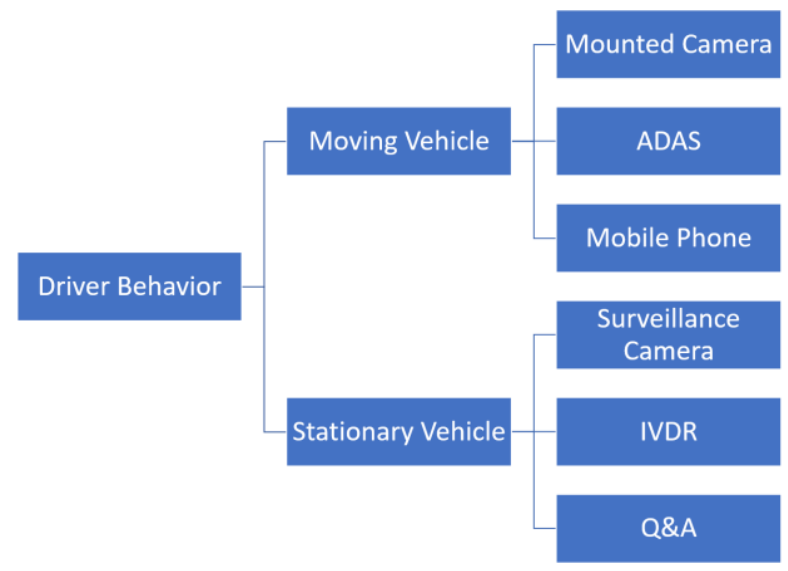

Figure 2 : Classification of Driver Behavior 
ADAS, in this approach of Advance Driving Assistance Systems [9], the authors proposed a driver assistance system to increase the safety. ADAS can be customized as per the driver's personal style. It will help the driver while driving and during the parking as well. Focus is to keep the car safety. This feature alerts the driver of the potential problems and to avoid the collision. ADAS includes the features as shown in Figure 3.

Advantage using this approach is high detection accuracy.

Disadvantage is computational complexity.

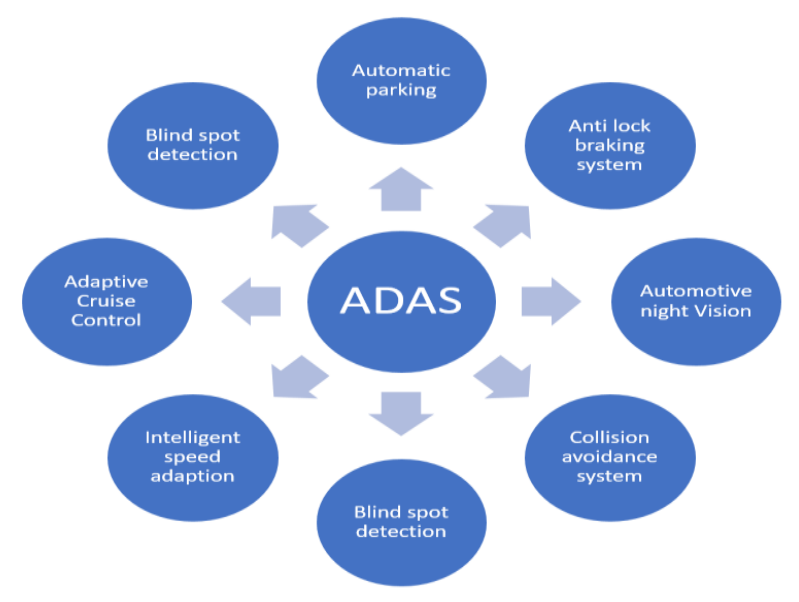

Figure 3 : ADAS features

Third approach is to detect the driver behavior based on the in-build mobile phone sensors. In [10] the authors proposed a mobile phone based feature on the drink and drive behavior. In [11] a system is developed to detect and analyze the road conditions and driver behaviors that can be dangerous to the driver's health or the neighboring public. The main objective is to notify the driver to change his driving behavior.

Advantage using this approach is provide the audio feedback and cost effective
Disadvantage is position of phone in front of dashboard.

\section{Stationary Vehicle:}

The technique is based on the technologies used to detect the driver behavior while he was driving the car and the sample data have been taken to provide as the feedback.

IVDR, In- Vehicle data recorders are the devices on board that is used to collect and record the movement, control and performance of the vehicle [12].

Advantage using this approach is record data in a continuous loop, overwriting information nonstop until a vehicle is involved in a collision

Disadvantage to use this approach is traditionally it was not equipped with a GPS device. So difficult to track the vehicle.

Surveillance Camera, many roads are now having the surveillance camera to keep an eye on the outside environment. To record the vehicle movement either rash driving or the safe driving can be notified to the driver on timely basis, this helps to detect the driver behavior in case of rash driving.

Advantage using this approach is records the information and provide the feedback.

Disadvantage is majority of camera monitor a limited area and high cost.

Questionnaire, in [13] a quantification method of driver characteristics based on the questionnaire is being proposing to identify the behavior to the driver. It is helpful to provide the feedback to the driver based to improve the safety.

Advantage using this approach is cost effective.

Disadvantage is environment factors not considered and late feedback to driver.

\section{CONCLUSION}

The above study describes the driver detection behavior based on the car moving and the stationary condition. There are numerous techniques present in the market today to check and alert the behavior of 
the driver. When it comes to cost only few of the techniques can be considered. When the vehicle is stationary that time it might not be useful at that instance, but if someone must give the driver feedback later point in time so can be given efficiently. As safety is paramount for everyone so it is essential a correct approach needs followed. The approach should be cost effective and the safety provider to all the passengers. The above-mentioned techniques like mounted camera in the car provides an alert to the driver and is also cost effective. Based on the Advantages and disadvantage mentioned the OEM's can consider the efficient techniques to analyze the driver behavior.

\section{REFERENCES}

[1]. "Road Accidents in India" in Government of India Ministry of Road Transport \& Highways Transport Research Wing, New Delhi, 2018.

[2]. D. Mitrovic, "Reliable Method for Driving Events Recognition", IEEE Trans. In tell. Transport Syst., vol. 6, no. 2, pp. 198-205, 2005.

[3]. G. Yang, Y. Lin and P. Bhattacharya, "A driver fatigue recognition model based on information fusion and dynamic Bayesian network", Information Sciences, vol. 180, no. 10, pp. 19421954, 2010.

[4]. J. C. Stutts, D. W. Reinfurt, L. Staplin and E. A. Rodgman, The role of driver distraction in traffic crashes, 2001.

[5]. "Driver fatigue and road accidents: A literature review and position paper", R. Soc. Prevention Accidents, pp. 1-24, Feb. 2001.

[6]. D. Mohan, "Analysis of road traffic fatality data for Asia", J. Eastern Asia Soc. Trans. Stud., vol. 9, pp. 1786-1795, 2011.

[7]. W. Rongben, G. Lie, T. Bingliang and J. Lisheng, "Monitoring Mouth Movement for Driver Fatigue or Distraction with One Camera", 7th International IEEE Conference on Intelligent Transportation Systems, pp. 314-319, 2004.
[8]. M.S. Devi and PR. Bajaj, "Driver Fatigue Detection Based on Eye Tracking", IEEE First InternationalConference on Emerging Trends in Engineering and Technology, pp. 649-652, 2008.

[9]. T. Bär, D. Nienhüser, R. Kohlhaas and J.M. Zöllner, "Probabilistic Driving Style Determination by means of a Situation Based Analysis of the Vehicle Data", 14th International IEEE Conference on Intelligent Transportation Systems, pp. 1698-1703, 2011.

[10]. J. Dai, J. Teng, X. Bai, Z. Shen and D. Xuan, "Mobile phone based drunk driving detection", 4th InternationalConference on Pervasive Computing Technologies for Healthcare, pp. 1-8, 2010.

[11]. M. Fazeen, B. Gozick, R. Dantu, M. Bhukhiya and M. González, "Safe Driving Using Mobile Phones", IEEE Trans. In tell. Transport Syst., vol. 13, no. 3, pp. 1462-1468, 2012.

[12]. Tomer Toledo and Tsippy Lotan, "In-Vehicle Data Recorder for Evaluation of Driving Behavior and Safety" in Transportation Research Board of the National Academies, Washington, D.C, 2006.

[13]. L. Zhang, J. Wang, F. Yang and K. Li, "A quantification method of driver characteristics based on Driver Behavior Questionnaire," 2009 IEEE Intelligent Vehicles Symposium, Xi'an, 2009, pp. 616-620, doi: 10.1109/IVS.2009.5164348.

\section{Cite this article as :}

Ishita Seth, " A Survey on Driver Behavior Detection Techniques", International Journal of Scientific Research in Science and Technology(IJSRST), Print ISSN : 23956011, Online ISSN : 2395-602X, Volume 7, Issue 3, pp.401-404, May-June-2020. Available at doi : https://doi.org/10.32628/IJSRST207384 Journal URL : http://ijsrst.com/IJSRST207384 